\title{
- European Waste Statistics data for a Circular Economy Monitor: opportunities and limitations from the Amsterdam Metropolitan Region
}

\author{
${ }_{4}$ Rusne Sileryte $^{a, b, *}$, Arnout Sabbe ${ }^{a, b}$, Vasileios Bouzas ${ }^{a}$, Kozmo Meister ${ }^{a}$, \\ 5 Alexander Wandl ${ }^{a}$ and Arjan van Timmeren ${ }^{a, b}$ \\ ${ }^{a}$ Faculty of Architecture and the Built Environment, Delft University of Technology, Delft, the Netherlands \\ ${ }^{b}$ Amsterdam Institute of Advanced Metropolitan Solutions, Amsterdam, the Netherlands
}

\section{ARTICLE INFO}

\section{Keywords:}

Circular Economy Monitor

European Waste Statistics

Amsterdam Metropolitan Region

Circular Economy Action Plan

Waste Mapping

\begin{abstract}
AB S T R ACT
As appointed in the EU Circular Economy Action Plan, cities and regions in EU member countries start accompanying their circular economy strategies by monitoring frameworks, often called Circular Economy Monitors (CEM). Having the task to assess the performance towards the achievement of set targets and to steer decision-making, CEMs need to rely on a multitude of statistics and datasets. Waste statistics play an important role in circular economy monitoring as they provide insights into the remaining linear part of the economy. The collection of waste statistics is mandated by the European Commission which provides general guidelines on data collection and processing. The Netherlands has one of the most detailed waste registries among the EU countries. The country's largest metropolitan region, Amsterdam, is currently building a CEM which tracks progress over time towards the set goals, highlights which areas need improvement and estimates target feasibility. This paper uses the Amsterdam CEM as a casestudy to explore how the existing system of waste registration in the Netherlands is able to support decision-making. The data is explored with the help of four queries that relate to the CEM's goals and require data mapping to be answered. The data mapping and analysis process has revealed several limitations present in the waste data collection and a number of gaps present in current circular economy research and data analysis. At the same time, the available data already supports significant insights into the status quo of the current waste system and provides opportunities for circular economy monitoring.
\end{abstract}

\section{Introduction}

The EU Circular Economy Action Plan (CEAP), published as part of the European Green Deal strategy ((COM/2020/98), describes targets, actions and challenges to decouple economic growth from resource use. The CEAP outlines what the European Union (EU) needs to achieve to become a sustainable economic system and ensure long-term competitiveness. The outlined actions apply to the EU as a single system with shared regulatory frameworks, financial measures, and trade agreements. The success of the plan implementation is intended to be monitored by the Monitoring Framework for the Circular Economy which builds up as much as possible on European statistics.

Being a supranational document, the CEAP has rippling effects on national, regional and local policies throughout Europe. A number of cities and urban regions have already announced their own

*Corresponding author

@R.Sileryte@tudelft.nl (R. Sileryte); Arnout.Sabbe@tudelft.nl (A. Sabbe); .Bouzas@tudelft.nl (V. Bouzas); K.R.Meister@tudelft.nl (K. Meister); A.Wandl@tudelft.nl (A. Wandl); .vanTimmeren@tudelft.nl (A.v. Timmeren)

ORCID(s): 0000-0002-8245-3016 (R. Sileryte); 0000-0001-7237-320X (A. Sabbe); 0000-0002-5639-8391 (V. Bouzas); 0000-0002-6342-7867 (K. Meister); 0000-0003-1163-0529 (A. Wandl); 0000-0002-0591-4923 (A.v. Timmeren) 
circularity ambitions and strategies to enhance circularity on a local level (Petit-Boix and Leipold, 2018) while others will be mandated by the Commission to prepare plans for "making the best use of EU funds" (European Commission, 2020). Since the organisation of the material flows in every city and region is dependent on the local conditions (Tapia et al., 2021), "the best use" will have to be determined by measuring and comparing the impact significance in the local context (Sileryte et al., 2018).

Monitoring frameworks are a crucial component of the CE strategies of many European cities. Their main purpose is to assess how the city is performing towards the achievement of set targets and to steer the decision making based on the measurements (OECD, 2020). The City of Amsterdam in the Netherlands has created a monitoring framework as part of its Circular Strategy 2020-2025 and is currently on the way to implement a digital Circular Economy Monitor (CEM) (Gemeente Amsterdam, 2020). The CEM tracks progress over time towards the set goals, highlights which areas need improvement and estimates target feasibility.

The Amsterdam CEM is expected to use a wide variety of public and private datasets integrated into a single framework. One of the largest and most detailed utilised datasets represents industrial waste production, disposal and treatment flows. Collection of this data is mandated by the EC Regulation No 2150/2002 on Waste Statistics, which enables Eurostat to collect biannual statistics on waste generation and treatment per economic activity, treatment method, and population served. The regulation provides general guidelines, however, each country applies a different data collection method. While most Member States collect waste data using sample surveys, the Netherlands employs a consistent waste registration from every company that has a waste permit (Nuss et al., 2017). These companies are statutorily required to register all transported waste at the Division of Waste Management (NL: Landelijk Meldpunt Afvalstoffen (LMA)) within the Dutch Ministry of Infrastructure and Public Works (NL: Rijkswaterstaat).

While the collection of waste data is initially meant for supranational monitoring and legislative purposes, the same data collection infrastructure is now being used for local decision-making purposes. Moreover, the infrastructure has been set up before including the CE strategies into policy making. In the light of the Circular Economy transition, this paper attempts to use the existing waste reports to answer Amsterdam CEM queries and this way explore how the existing system of waste registry in the Netherlands is able to support city-scale decision making.

After investigating the raw data, relevant data mapping processes are proposed based on the CEM goals. The mapping results are visualised to explore the strengths and limitations of the available data. Finally, an extensive discussion is provided on the possible improvements in the data collection system on a local and national scale. Given the data collection is mandated on a European scale, the recommendations can be taken into account for any European city CEM and European-wide guidelines.

\section{Key objectives of Circular Economy Monitoring}

The OECD Report on the Circular Economy in cities and regions (OECD, 2020) distinguishes four key objectives in monitoring CE: triggering actions; making the case for the circular economy; monitoring performance and evaluating results; and raising awareness. The same objectives, although termed differently, are set forward in the Amsterdam CEM: determining the CE decision-making space; evaluating the feasibility of local CE strategies; assessing the social and ecological impact; and communicating the results to the public (Gemeente Amsterdam, 2020). The focus of this research lies on the first three goals and objectives, leaving awareness and public communication beyond the current scope. The following three subsections explore how data has been used in other related research to achieve the mentioned objectives, while the last subsection summarises the most important data requirements. Based on the provided summary, this paper studies how the most granular available waste flow data collected for Eurostat reporting purposes corresponds to the requirements set forward in the reviewed studies. 

are considered (Obersteg et al., 2019). available, at different scales (Akram et al., 2019).

\subsection{Determining the $\mathrm{CE}$ decision making space}

Triggering actions based on monitoring data relates to the meta-choices of the decision making process (Ferretti and Montibeller, 2016) such as assigning decision boundaries and scales, identifying relevant stakeholders, and formulating concrete objectives. The optimal spatial scale and decision boundaries of CE strategies depend on a number of variables such as the current extent of material flows (Wandl et al., 2019; Furlan et al., 2020), material processing capacity (Graedel et al., 2019), material market value and transportation costs (Rahman and Kim, 2020) and to which extent the indirect impacts

While Obersteg et al. (2019) and Wandl et al. (2019) emphasize that in comparison to cities, urban regions are a more sustainable spatial scale to act for the actualisation of CE actions, Graedel et al. (2019) demonstrated that a circular economy is difficult to impossible to achieve at the scale of a single country. Furthermore, Zeller et al. (2019) have noticed that there is no optimal scale that fits all resource types. Waste with high market value, specialised industrial processing, and relatively low transportation cost, such as metal or glass, will be recovered at a large scale (Rahman and Kim, 2020). Waste with low market value, high accumulation density and costly transportation, such as organic or bulky waste, is more suited for closing material loops locally.

At the same time, Morseletto (2020) has noticed that all end-of-life products and materials cannot fall under the same targets and policies. E.g., organic waste clearly cannot be "refurbished" or "repaired", scrap from the production process cannot be "reused" and renewable materials should not be "refused" if they are substituted by critical raw materials. This asks for the distinction of targets - and therefore metrics - at least by material groups and economic sectors. The need for more granular data regarding the waste content has also been acknowledged by (Alexander and O'Hare, 2020) who notice that blind spots are created by privileging one kind of measurement over the other and therefore "a more open acknowledgement of different kinds of material characteristics and different methods of evaluation that attend to qualities, might help sidestep certain wasting processes."

\subsection{Evaluating the feasibility of local CE strategies}

Making the case for the circular economy requires understanding of the costs and benefits of scoping which $\mathrm{CE}$ activities may be feasible in terms of sufficient quantity and quality of a given material to allow for a given technology of reuse, recycling or transformation. A typical example of secondary resource supply and demand matching are recommender systems for industrial symbiotic networks. They recommend the best suitable alternative destination for industrial waste instead of a conventional waste disposal option based on such information fields as waste codes, user assigned keywords and descriptions, waste/material quantities, generation frequency, and site location (Gatzioura et al., 2019; van Capelleveen, 2020; Yeo et al., 2019; Maqbool et al., 2019).

The same data characteristics are relevant in regional assessments when the total amount of potentially available secondary resources are compared with the current primary resource demands. To evaluate the feasibility of circular strategies both high spatial and high temporal resolutions of material flow data are necessary (Voskamp et al., 2016; Yu et al., 2021; Akram et al., 2019). Understanding the spatial and temporal dynamics that can be influenced by external governmental incentives also serves the design of circular supply chains Yu et al. (2021). Finally, increasing input data resolution creates a more realistic picture of recycling needs and cost efficiency, therefore it is important to have high quality data on resources, in terms of quantity, quality, geolocation, and time of resources becoming

The geopolitical scale is also an important aspect while considering closing material loops. While Graedel et al. (2019) argue that no country anywhere has a complete collection of the technologies that would be needed to achieve circularity for all the required materials, Schaubroeck (2020) notices that if a loop is closed outside of Europe, "it can be concluded that there is no circular economy within Europe for that material, yet on a global level, it is the case." Therefore, the availability of technologies, 
material criticality and socio-economic conditions are relevant not only in the local context of decision making but also beyond (Schaubroeck, 2020).

\subsection{Assessing the impacts}

The third goal of a CEM comes from an obligation to study the impacts caused by circular resource use (Harris et al., 2020). On the one hand, circular resource use is expected to substitute primary resource use and extraction, and this way reduce the associated environmental impacts. On the other hand, the specialised technologies necessary to upscale resources are not always available locally (Rahman and Kim, 2020) and circular practices may lead to undesired rebound effects (Schaubroeck, 2020). Therefore, transport and energy environmental impacts must be assessed to evaluate the actual environmental impact of circular material use (Graedel et al., 2019), and geopolitical, socioeconomic, and trade-off aspects need to be covered to conclude whether circularity leads to improved sustainability (Schaubroeck, 2020). Moreover, the CE itself impacts the spatial structure of the social (employment, occupational health, accessibility, etc.) and material (infrastructure, built environment, etc.) contexts in which it is implemented (Jedelhauser and Binder, 2018).

Pincetl and Newell (2017) argue for using big data that is also granular to place and spatially explicit on production and consumption patterns across urban landscapes, so that it reveals processes by connecting actors, activities, and impacts across time-space and reveals their resulting political, industrial, and ecological implications. Their research has found that big data that encompasses the institutional and ecological context of urban activities provides a framework to explore questions of equity and policy development and help enable reform by identifying patterns and drivers of use.

CE impact assessment falls within the field of socio-economic metabolism (SEM) studies (Haberl et al., 2019). It is most often performed by using a combination of Material Flow Assessment (MFA), Life Cycle Assessment (LCA) and Input-Output Analysis (IOA) methods (Corona et al., 2019). All of these methods are data-intensive and require integration and semantic correspondence between a number of interdisciplinary datasets (Corona et al., 2019; Pauliuk et al., 2016). Although model and data harmonisation between different SEM fields lately has been advanced (Krausmann et al., 2018), there is still no single nomenclature or formal ontology of the used terms and concepts (Pauliuk et al., 2016; Sileryte et al., 2021a).

To improve data integration and reduce uncertainty, Pauliuk et al. (2019) have suggested a general data model for SEM studies that requires all datasets to be described along five dimensions: 1) the time dimension, 2) the location dimension, 3) the process dimension, 4) the object (substances, materials, goods, products, or commodities) dimension, and 5) the layer (unit) dimension. Along with publishing values and their metadata, they suggest that data providers should store correspondences between different classifications.

\subsection{Data requirements for the Circular Economy Monitoring}

Although the data requirements are labelled differently in different studies, there are common denominators that relate to all monitoring purposes:

1. Studying flows, relations, and transformations rather than static numbers is the most commonly mentioned requirement necessary for all monitoring purposes. Studying geographical flows is necessary for the determination of the decision making scale and circularity metrics. Relations between economic sectors and activities allow understanding how the decision effects trickle down to the material flow networks, and how innovation and cooperation can be stimulated. Material transformation processes mostly relate to the environmental and social impacts of the material flows. They also describe material quality and capacity to substitute virgin resources.

2. Material quantity in both mass and volume and material market value are the most important measurement units that relate to the feasibility of the CE strategies and the eventual environmental impacts. 
3. As detailed information as possible on the material content is a key aspect that is necessary to determine the best applicable treatment or up-cycling process, connect material supply with demand and calculate impact on the primary resource depletion.

4. High level-of-detail temporal and geographical information about the material locations and movements is necessary to determine the decision making boundaries and relevant stakeholders, transportation and processing costs, material accumulation density and storage capacities. Information on the flow frequency allows monitoring changes over time and therefore evaluating the progress. At the same time it is important for setting targets and assessing their feasibility.

5. Finally, the integration of multiple datasets and assessing the quality of monitoring itself requires the availability of metadata that describes the data collection process, units and used nomenclature.

Such requirements are desirable for the data to support city-scale decision making. Although CEAP stresses the importance of monitoring and data availability to support the decision-making on all governance levels, very few researchers discuss whether the datasets enabled by Eurostat allow for the required monitoring. The system of Economy-Wide Material Flow Accounts (EW-MFA) (Eurostat, 2018), which have been published by most European countries, have improved the data availability, but the data is only available aggregated at country scale (Zeller et al., 2019). To date, there are very few published examples of high granularity waste flow data being used in support of city-scale CE decision making. Geldermans et al. (2018) have been using the Dutch waste registry for spatial, social and material flow analysis in Peri-Urban Living Lab (PULL) workshops. Geldermans (2020) has further mapped specific economic activities relating to material flows and stocks from waste production in cities' subsystems, as well as the involved actors and their interrelations regarding the circular indoor partitioning. Furlan et al. (2020) has used the same dataset to map and study waste flows as part of the urban metabolism in the Amsterdam Metropolitan Area. The three studies conclude that the dataset is useful, especially due to its explicit spatial dimension, however, do not further discuss its limitations and opportunities.

\section{Methods}

The primary purpose of industrial waste data collection is not supporting CEM purposes but providing insights into waste management activities. Therefore it is expected that to answer the questions of the monitor's users, the data needs to undergo the process of mapping (Sileryte et al., 2021a). Mapping refers to a mathematical correspondence that assigns exactly one element of one set to each element of the same or another set (Merriam-Webster). Basically, the need for data mapping arises when the question at hand has to be answered using the terms or values which are not used in the original dataset.

The process of mapping always requires three fundamental elements: an object (or multiple objects) to be mapped (domain), a set towards which the object is mapped (co-domain) and a mapping function which describes the relationship between each object and the sets. The quality of the mapping is directly dependent on the quality of those elements. In case of this research, the values in the industrial waste dataset are the objects to be mapped. The sets towards which the mapping is performed and the functions used for mapping depend on the query at hand.

Four general queries have been formulated together with the CEM development team at the City of Amsterdam that could be answered using industrial waste reports. The queries relate to the different purposes of city-scale circularity monitoring as defined in the Amsterdam Circular Economy Strategy (Gemeente Amsterdam, 2020). The four queries (Table 1) should be viewed as typical examples rather than an exhaustive list. Four experiments of data mapping have been chosen as the most relevant to answer the formulated queries.

The experiments are executed in the four following steps. First, the waste reports are acquired in their raw state and relevant datasets are selected as necessary for the mapping functions. Next, the 
Evaluating the feasibility for local CE strategies

Assessing the social and ecological impact Netherlands.

\section{Table 1} a relevant set of values.

raw data is cleaned, filtered and harmonised to avoid corrupted data points and fix inconsistencies. Afterwards, the selected mapping functions are applied. All information is combined in a single comprehensive table that can be further used to do statistical analysis and produce data visualisations. The observations and the limitations encountered during the mapping process are used for an extensive discussion about the current potentials and limitations of the current waste reporting system in the

Overview of the four experiments that aim to answer CEM queries by mapping waste registry dataset into

\begin{tabular}{|c|c|c|c|c|}
\hline CEM goal & Query & $\begin{array}{l}\text { Mapping } \\
\text { domain }\end{array}$ & $\begin{array}{l}\text { Mapping func- } \\
\text { tion }\end{array}$ & Mapping co-domain \\
\hline $\begin{array}{l}\text { Determining the } \\
\text { CE decision-making } \\
\text { space: geographical } \\
\text { scope and scale }\end{array}$ & $\begin{array}{l}\text { What is the spatial } \\
\text { extent of the waste } \\
\text { flows that originate } \\
\text { within the municipal- } \\
\text { ity of Amsterdam? }\end{array}$ & $\begin{array}{l}\text { Company } \\
\text { addresses }\end{array}$ & Geolocation & $\begin{array}{l}\text { Geographical coordi- } \\
\text { nates }\end{array}$ \\
\hline $\begin{array}{l}\text { Determining the } \\
\text { CE decision making } \\
\text { space: stakeholders }\end{array}$ & $\begin{array}{l}\text { Which economic sec- } \\
\text { tors need to be in- } \\
\text { cluded in the circular } \\
\text { economy strategy de- } \\
\text { velopment and deci- } \\
\text { sion making? }\end{array}$ & $\begin{array}{l}\text { Waste producer } \\
\text { names and ad- } \\
\text { dresses }\end{array}$ & $\begin{array}{l}\text { Entity linking } \\
\text { using the } \\
\text { Chamber of } \\
\text { Commerce } \\
\text { (KvK) business } \\
\text { registry }\end{array}$ & $\begin{array}{l}\text { Economic sectors } \\
\text { according to NACE } \\
\text { (Nomenclature } \\
\text { statistique } \\
\text { des activités } \\
\text { économiques dans } \\
\text { la Communauté } \\
\text { européenne) }\end{array}$ \\
\hline $\begin{array}{l}\text { Evaluating the fea- } \\
\text { sibility for local CE } \\
\text { strategies }\end{array}$ & $\begin{array}{l}\text { Which secondary } \\
\text { materials are present } \\
\text { in the area and have } \\
\text { the potential to be } \\
\text { reused? }\end{array}$ & EWC codes & $\begin{array}{l}\text { Manual seman- } \\
\text { tic annotation }\end{array}$ & $\begin{array}{l}\text { Classes that describe } \\
\text { waste reuse potential }\end{array}$ \\
\hline $\begin{array}{l}\text { Assessing the social } \\
\text { and ecological im- } \\
\text { pact }\end{array}$ & $\begin{array}{l}\text { What is the current } \\
\text { carbon emission im- } \\
\text { pact of waste trans- } \\
\text { portation? }\end{array}$ & $\begin{array}{l}\text { Waste } \\
\text { production } \\
\text { and treatment } \\
\text { locations, } \\
\text { number of } \\
\text { transport trips } \\
\text { and weight per } \\
\text { trip }\end{array}$ & $\begin{array}{l}\text { Shortest } \\
\text { distance } \\
\text { estimation and } \\
\text { probable vehicle } \\
\text { assignment } \\
\text { based on } \\
\text { transported } \\
\text { weight }\end{array}$ & $\begin{array}{l}\text { Carbon emissions } \\
\text { from transport, } \mathrm{CO}_{2} \\
\text { equivalent }\end{array}$ \\
\hline
\end{tabular}

\subsection{Data Acquisition}

\subsubsection{Dutch National Waste Registry}

The industrial waste statistics in the Netherlands are currently carried out under the framework of the Waste Statistics Regulation (Eurostat, 2013) and are used in the annual monitoring of the National Waste Management Plan (NL: Landelijk afvalbeheerplan (LAP)). The Division of Waste Management (NL: Landelijk Meldpunt Afvalstoffen (LMA)) within the Dutch Ministry of Infrastructure and Public Works (NL: Rijkswaterstaat) is responsible for the reporting of industrial waste. Every waste management company in the Netherlands is obliged to file a waste report after receiving a significant amount of waste (i.e., more than $50 \mathrm{~kg}$ ) which is legally processed as waste and not as a secondary 
raw material. The reports represent a chain of waste management companies from the original waste producer all the way to the final treatment destination. LMA estimates that around $60 \%$ of all waste produced or treated in the Netherlands is reported to them. The reports are not publicly accessible as they contain company-sensitive information.

The LMA dataset has been filtered for all waste produced and/or treated in Amsterdam Metropolitan Area (AMA) in year 2018 and consists of two subsets:

Receipt Notifications (NL: Ontvangst Meldingen) are reports of primary and secondary (waste from waste treatment facilities) waste submitted by waste processors that receive industrial waste and are obliged to report waste under the Dutch law.

Issue Notifications (NL: Afgifte Meldingen) are reports of secondary waste coming from the waste treatment facilities. These reports need to be filed when: a) secondary waste is up-cycled and sold as a product; $b$ ) the secondary waste is further processed by a company that is not obliged to report to the LMA; this especially applies to companies outside of the Netherlands. Secondary waste is reported either using EWC (European Waste Classification) codes or GN (General Nomenclature) codes, depending on the applicable legislation.

All data that has been used for this case study has been provided by the LMA under the framework of the Baseline for the Amsterdam Circular Economy Monitor project in collaboration with the Amsterdam City Chief Technology Office (CTO).

\subsubsection{Chamber of Commerce Registry}

The LMA dataset does not contain any additional information on the companies that produce waste except for their name and address. This poses a limitation to determine the actual waste origin and especially the economic activity that is responsible for the waste generation. To provide the missing information, LMA dataset is linked with the data from the Chamber of Commerce (NL: Kamer van Koophandel (KvK)) as suggested by the Eurostat guidelines (Eurostat, 2013). It is a trade register which holds the registry of all companies and their addresses in the Netherlands. The KvK dataset has been limited to the extent of the Amsterdam Metropolitan Area in 2018.

\subsubsection{Road Network}

A simplified road network is used to assess the carbon emissions caused by the waste transportation. The original data for the Dutch road network is provided by OpenStreetMap (OSM) and GEOFABRIK. From all available OSM tags related to road networks, only the following have been extracted: motorway, trunk, primary and secondary. On this subset, a custom simplification algorithm has been applied which 1) merges contiguous segments into linestrings, 2) collapses junctions into single points through clustering, and 3) simplifies line segments based on the Douglas-Peucker algorithm.

\subsection{Data Processing}

The waste reports do not undergo any quality or validity checks before or after being submitted. As long as all required fields are filled, a report is permitted for submission. Therefore, errors of various nature are common. While it is not possible to check how well the reports represent reality, a number of sanity checks can be applied in an automated process to remove or rectify faulty entries and harmonise values that are likely representing the same entities.

Filtering removes blunders that would confuse further processes and affect the analysis results. Blunders are considered those entries that have invalid postcodes, company names without alphabetical characters or waste amounts that are below $1 \mathrm{~kg}$ or above $45 \mathrm{t}$ per transport event. These thresholds are selected in consultation with the LMA representatives. Cleaning removes all non-alphanumeric characters and repeating white-spaces from the free form text fields and compares data fields to identify such cases as company name entered instead of the street name and similar ones. Harmonisation unifies the capitalisation and formatting of such fields as postcodes and addresses. Additionally, it attempts 
to harmonise company names by removing the acronyms related to the company legal structure (i.e., BV, VOF, NV, SV, CV) and apostrophed articles ('t and 's) common in Dutch language.

\subsection{Data Mapping \\ 3.3.1. Geospatial Mapping}

The necessity to know the geospatial location where waste is produced, transported and treated is mentioned in relation to all CEM goals. Geospatial representation of waste flows is able to answer the queries related to scale, understanding the decision making context, and finally, it helps answering the question whether secondary material supply meets the demand within certain geographical boundaries.

The LMA data provides information on the waste disposal and treatment locations by using building or site addresses. Geolocation allows the conversion of addresses into unique points with geographic coordinates in a chosen coordinate reference system using a service database with all available addresses. The Mapbox Geocoding API has been chosen for the mapping of all waste disposal and waste treatment locations available in the LMA dataset.

Geocoding is prone to errors that happen if an address is not complete, misspelled, corresponds to multiple points or it is simply not included in the service database. To validate geocoding results and rectify the errors, additional spatial data were incorporated into the analysis; namely, the Dutch postcode districts (NL: Postcodegebied). Postcode districts are polygons that include all addresses within the same first four digits of a postcode. If a point falls within its own postcode polygon, then the location is considered valid. Otherwise, the geolocation is considered invalid and a postcode polygon centroid is assigned instead of the geolocated point.

\subsubsection{Mapping Waste Producers to their Economic Activities}

The EC Regulation No 2150/2002 on Waste Statistics enables Eurostat to collect statistics from member states on 1) waste generation per economic sector and household consumption; 2) waste treatment by waste category and type of treatment and 3) number and capacity of recovery and disposal facilities (per NUTS 2 region) and population served. However, waste treatment statistics are collected directly from the waste treatment facilities and therefore disconnected from the waste producers. Companies in the LMA dataset are reported only by their name and address but neither their economic sector nor unique identifiers are available to establish a link with other business registries.

Knowing which economic activities produce which kinds of waste is necessary to answer which economic sectors need to be specifically addressed due to their waste production. It also describes the characteristics of waste content (e.g. by distinguishing between post-consumer or production and distribution waste). From the impact assessment perspective, the economic sector should be able to describe the process that has been applied to the material, product, or substance before it has turned into waste.

The mapping method that has been used to connect waste producers to their economic activities is based on entity linkage between the LMA and KvK datasets using name similarity according to the Levenshtein distance and geospatial proximity as described in Sileryte et al. (2021b).

\subsubsection{Semantic Mapping of Waste Content}

The content of the reported primary waste stream is described using two information fields: a free text field and an EWC (European Waste Catalogue) code. The EWC code provides a standardised description of different types and sources of waste. The codes are used to decide on the most appropriate treatment process; identify the rules that apply to movement, storage, and treatment; and provide guidance on waste hazardousness. Although not intended for this purpose, EWC codes are often used for the identification of new symbiotic relations (Genc et al., 2019; Capelleveen et al., 2021). Two key limitations of this kind of EWC usage are mentioned in the literature: 1) the lack of information on the actual material content; and 2) possible overlaps between the codes.

The free text field does not have any additional guidelines; the reporting person is only asked to provide a description of the waste stream in their own words. Filling in the free text field is not 


\section{Table 2}

Semantic annotation system applied to the EWC codes to identify material reuse potential in the waste registry. All tags are indicative only as the actual re-usability potential would require a more thorough investigation of the particular contents within these waste streams and their alternative use.

\begin{tabular}{ll}
\hline Tag & Description \\
\hline Clean / Contami- & $\begin{array}{l}\text { Contamination indicates whether the waste content requires an additional } \\
\text { nated } \\
\text { cleaning process to be applied before the valuable material can be reused } \\
\text { for a different purpose. If no contamination is mentioned in the EWC } \\
\text { description, the stream is assumed to be clean. }\end{array}$
\end{tabular}

Pure / Mixed / Un- Material purity indicates that the waste stream contains only one type of known material (e.g. concrete, plastics, paper, food waste), also called a mono stream. Purity indicates that the waste stream does not need to undergo a separation process before it can be reused for a different purpose. If the description does not indicate anything about the material content, it is tagged as "unknown". Contaminated waste streams are by definition also mixed.

Biotic / Abiotic / Biotic substances (e.g. wood, agricultural crops, animal products) are Unknown renewable on a short term while abiotic substances (e.g. minerals, metals and fossil fuels) are not renewable on a short term. If the description does not indicate anything about the material content or the material content is expected to contain a mixture of biotic and abiotic materials, it is tagged as "unknown".

Organic / Inorganic / Organic substances are separated from the inorganic ones from a chemical Unknown point of view. The distinction between organic and biotic materials is necessary as some abiotic materials are organic in chemical structure, e.g. petroleum and other fossil materials. They are not renewable in the short term, although their chemical structure is more similar to the renewable biotic resources than to minerals and metals. If the description does not indicate anything about the material content or the material content is expected to contain a mixture of organic and inorganic materials, it is tagged as "unknown".

Material
This a free form semantic tag that describes which materials are expected in a given waste stream. 


\subsubsection{Mapping Waste Transport Needs to Carbon Emissions}

Studying waste transportation routes serves two purposes. First, it allows estimating the costs associated with waste transport and collection and therefore the financial feasibility of the strategies. Second, it relates to the energy needs for moving materials and thus the associated emissions which cause negative environmental impacts. To answer the query about the current carbon emission impact of waste transportation, this paper attempts to provide the mapping of waste flows to the anticipated amount of carbon emissions directly caused by waste transportation by heavy duty vehicles.

The basis for the computation is the emission factors per vehicle group as published by Klein et al. (2020). The STREAM (Study on Transport Emissions for All Modes) report provides emissions on various air pollutants (carbon dioxide, nitrogen oxides, etc.) for different modes of transport and vehicle groups of specified payloads. To assign waste flows to the most probable vehicle groups, payload sets are created with ranges from the minimum to the maximum capacity of a vehicle group. The maximum amount is assumed to be equal to the maximum payload of the given group and the minimum payload is assumed to be the maximum payload of the closest group of a smaller payload. The most probable vehicle is selected based on the reported waste amount per single transport trip.

The computation of the $\mathrm{CO}_{2}$ emissions results from the product of the following variables: 1) the estimated emissions of $\mathrm{CO}_{2}, \mathrm{CH}_{4}$ and $\mathrm{N}_{2} \mathrm{O}$ (summed as $\mathrm{CO}_{2}$-eq.) per tonne kilometre for an assigned vehicle group; 2) the distance in kilometres between the flow origin and destination following the shortest path; and 3) the waste amount per trip in tonnes. The shortest distance path is estimated using the Dijkstra shortest path algorithm and a simplified Dutch road network.

\section{Results}

The described data mapping methods have been applied on 215057 receipt notifications and 10295 issue notifications from the year 2018 where either the waste disposing company, the waste pickup location or the waste treatment location has been registered under a postcode that belongs to the Amsterdam Metropolitan Area.

$1730(0,8 \%)$ of all receipt notifications, and $532(5,2 \%)$ of all issue notifications have been discarded, mostly on the basis of missing waste disposal or treatment locations $(0,38 \%$ and $3,5 \%$ respectively) and unrealistic reported amounts (too small to be reported or too big to be transported by the reported number of transport trips) ( $0,4 \%$ and $1,6 \%$ respectively). Higher number of missing waste treatment locations within the issue notifications can be explained by a relatively large portion of secondary waste being exported abroad ( $8,9 \%$ of all issue notifications). Foreign addresses tend to be reported incompletely more often than local addresses.

The total amount of waste reported by the valid receipt notifications is $9419 \mathrm{Mt}$ of which $87,3 \%$ is primary waste and $12,7 \%$ is secondary waste. The total amount of waste reported by the valid issue notifications amounts to $3466 \mathrm{Mt}$. It is not known to which extent those amounts are overlapping.

\subsection{Query 1. What is the spatial extent of waste flows that originate within the municipality of Amsterdam?}

Geospatial mapping has resulted in a successful assignment of coordinate pairs to $98,7 \%$ of all addresses. Visualising the flows on a map allows for a very high level of detail, allowing to zoom in and trace flows on as granular as a building scale. To answer the first query Figure 1 depicts all waste flows reported by the receipt notifications that originate in the municipality of Amsterdam and distinguishes them according to the local treatment, treatment in the AMA and treatment elsewhere in the Netherlands. It can be observed that $57 \%$ (2 $135 \mathrm{Mt})$ of waste is treated locally, $17 \%$ (661 Mt) is transported from the municipality to the region, and the remaining 25\% (945 Mt) is treated elsewhere in the Netherlands. 


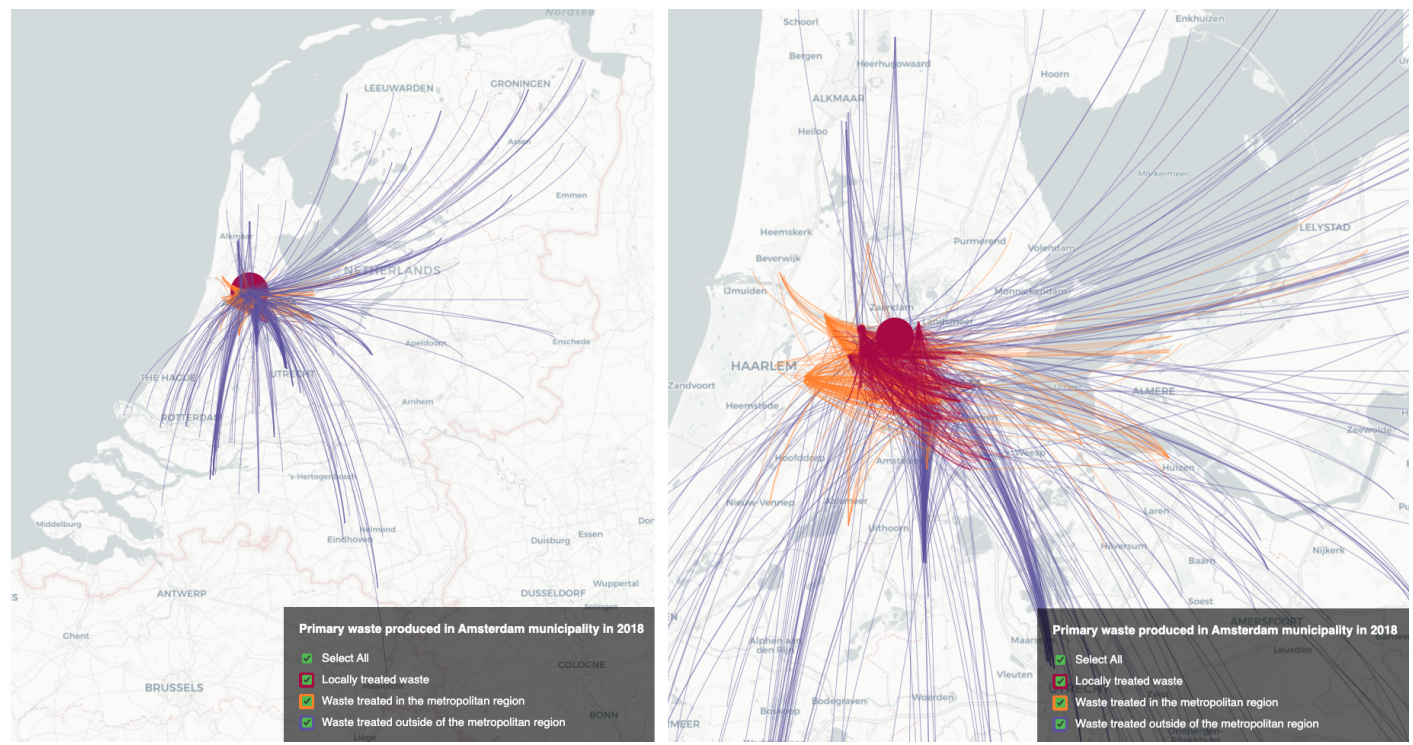

Figure 1: Waste flows that have originated in the municipality of Amsterdam in 2018. Line thickness corresponds to the total mass of waste transported between the two points, the darker side of the line presents the waste transport destination, the lighter side - waste transport origin. For readability purposes only flows bigger than $1 \mathrm{Mt}$ are rendered on the map. the Chamber of Commerce dataset ( 79\%).

\subsection{Query 2. Which economic sectors need to be included in circular economy strategy development and decision making?}

Assigning economic sectors to the waste disposing entities has been successful for a significant fraction (79.28\%) of all companies in the AMA of which $42.7 \%$ have been matched with high confidence, and $36.58 \%$ with low confidence. $20.72 \%$ of all companies remain unmatched. The unsuccessful matches stem for a small part from failed geolocations ( $1.3 \%)$, partly from heavily misspelled company names ( $20 \%$ ) and mostly from inconsistent company address registrations in

However, as discussed in Sileryte et al. (2021b), the unmatched entities do not show any different statistical patterns than the matched ones, neither in terms of reported waste types, nor their geographical distribution. Therefore, it is safe to assume that the successfully matched part could be used as a substantial sample for a statistical analysis. Figure 2 visualises the proportions of waste produced by the different economic sectors in the AMA and the applied processing methods.

\subsection{Query 3. Which secondary materials are present in the area and have the potential to be reused?}

Semantic annotation of waste content has been applied to 200 of the most common EWC codes (91\% of all primary waste flows) in the AMA. Mapping has resulted in a range of 148 materials with four additional properties, specifically, biotic, organic, purity and cleanliness. The resulting material list is neither collectively exhaustive nor mutually exclusive and serves as a guidance that the given material or product is likely to be the major compound of an indicated waste stream. Materials from construction and demolition activities such as concrete, bricks, stones, and soil are among the largest waste streams. 20 out of 200 EWC codes could not be assigned any material as their description indicates which materials the code is not supposed to contain (e.g. "19 12 12: Other wastes (including mixtures of materials) from mechanical treatment of wastes other than those mentioned in 191211 ") or a mixture of multiple unidentified materials (e.g. "20 03 06: Waste from sewage cleaning"). 


\section{European Waste Statistics data for a Circular Economy Monitor}

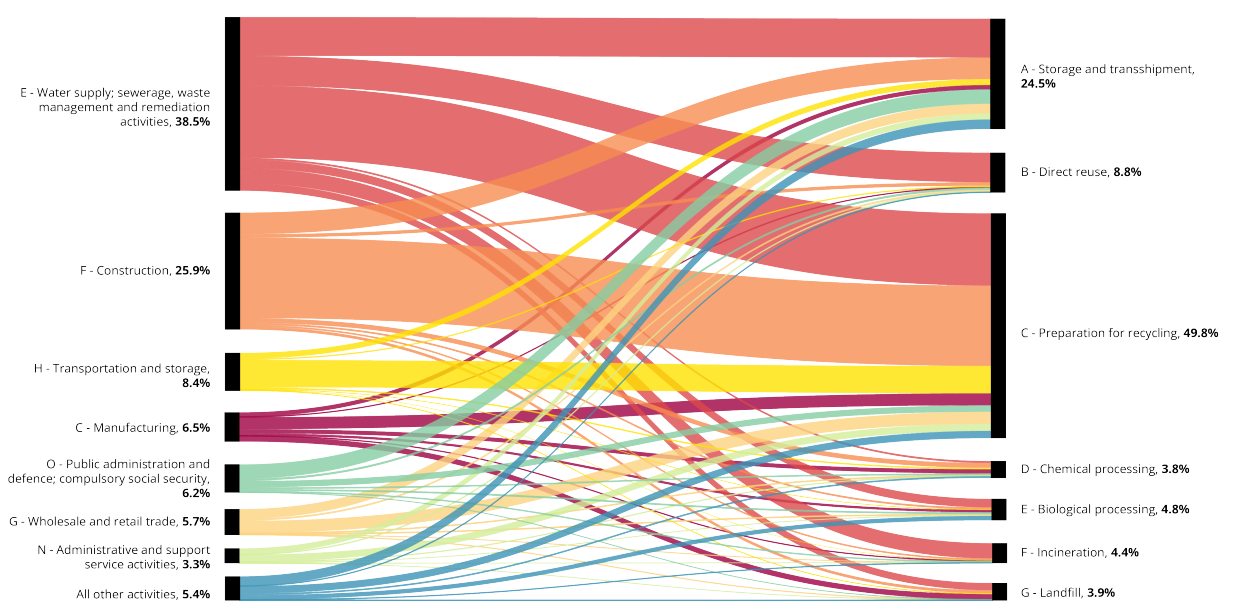

Figure 2: Waste distribution between economic sectors according to the NACE classification and the applied waste processing method. The distribution is based only on the high confidence matches.

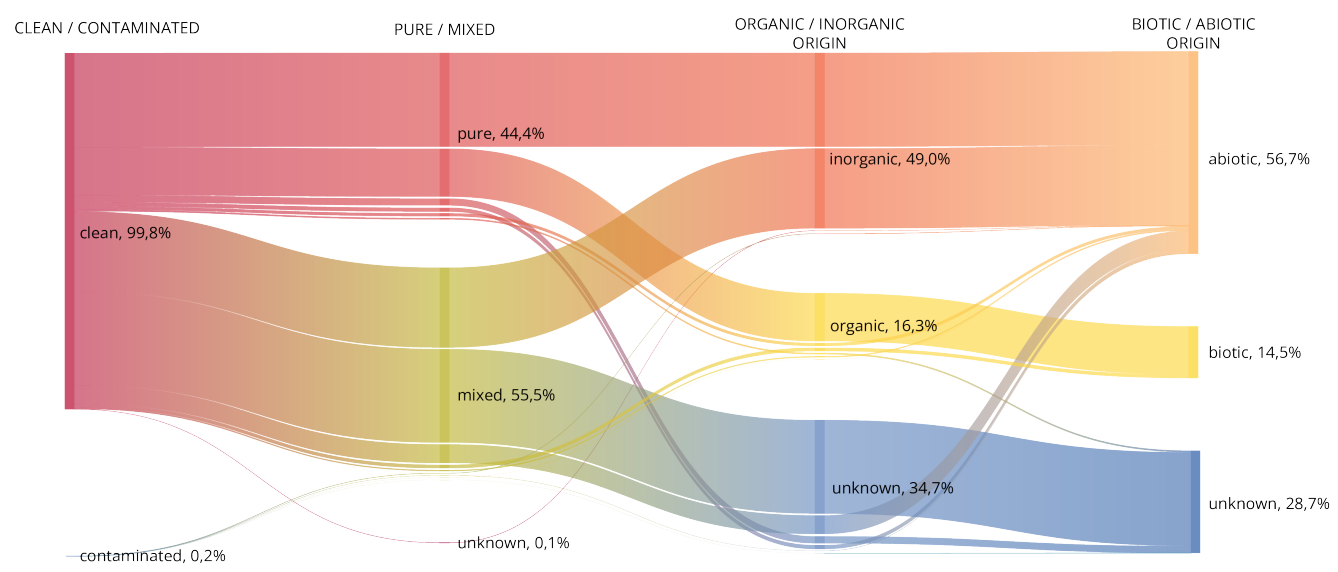

Figure 3: Parallel sets of the waste distribution according to the assigned semantic tags.

Biotic or organic origin could not be assigned to additional 47 codes mostly on the basis of material mixture of diverse origin (e.g. "07 04 13: Solid wastes containing hazardous substances from manufacture, formulation, supply, and use of organic plant protection products"). Purity and cleanliness could be assigned in all but one case since mixed or contaminated waste indicates the lack thereof.

Figure 3 shows how waste produced or treated in the AMA distributes between the assigned classes. The group containing clean pure abiotic inorganic resources is considered to have the highest potential for reuse and constitutes 20.3\% (2 $258 \mathrm{Mt}$ ) of all classified waste streams. Approximately $28 \%$ of all waste is reported without providing any information about its content. 

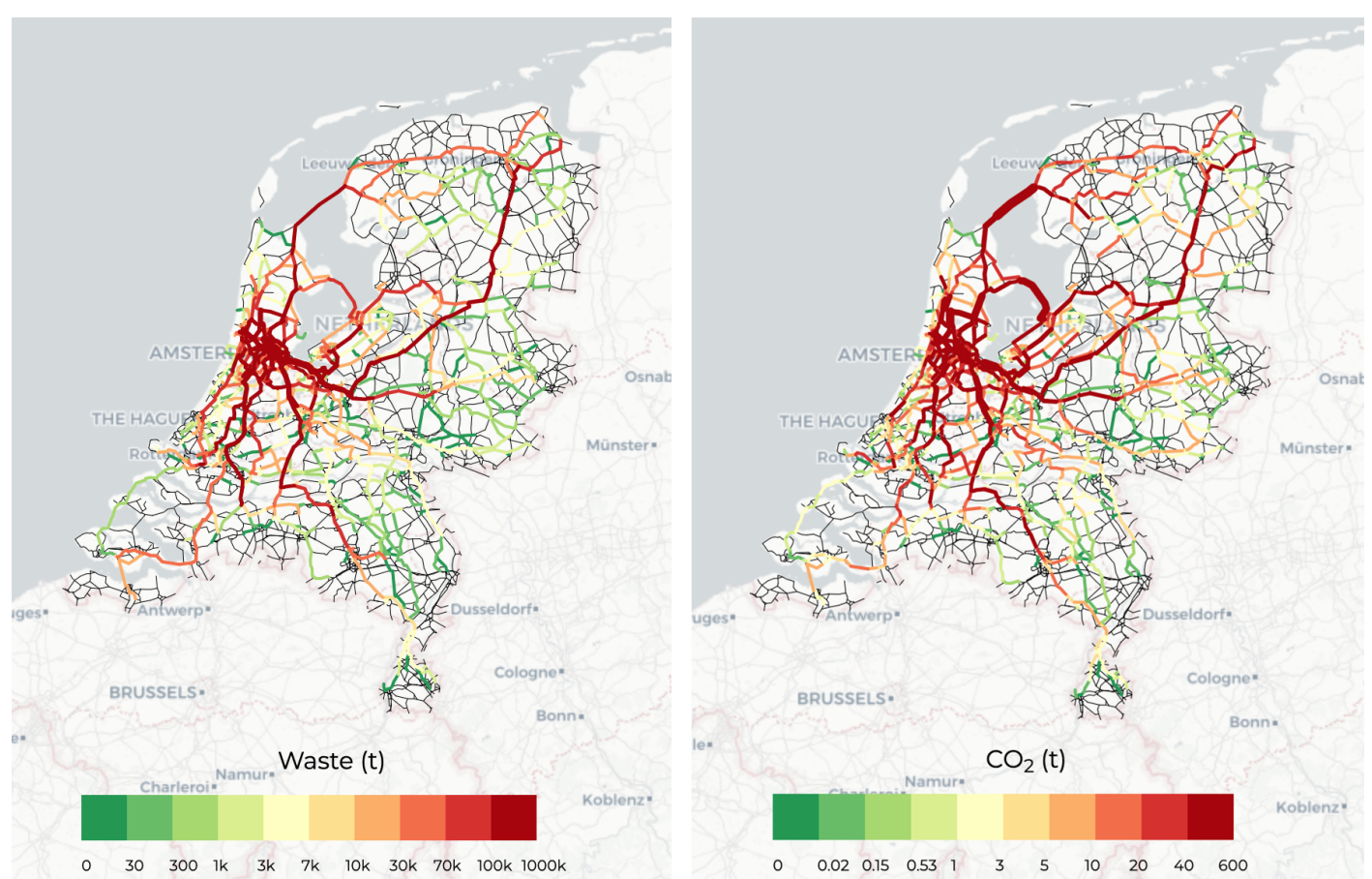

Figure 4: Road network map of the Netherlands coloured according to the amount of waste transported in 2018 (left) and the greenhouse gas emissions $\mathrm{CO}_{2}$ eq. caused by transportation (right). 


\section{European Waste Statistics data for a Circular Economy Monitor}

locations and transport flows between them. Therefore, the geographical mapping of waste reports allows visualising the scales of different waste scopes and assessing transport-related environmental impacts. The changes of the total mass of disposed waste can be traced over time, space and in relation to specific companies and waste treatment methods. While it does not allow measuring the circular use of resources, it allows monitoring the remaining linear part of the economy. Finally, the available free text field descriptions and EWC codes, which are used to describe waste, allow estimating the material content for roughly $70 \%$ of the total reported waste flow mass.

At the same time, the mapping process has revealed a number of limitations present in the waste data collection and a number of research gaps related to circular economy data analysis. First, the waste registry currently has low interoperability with other registries and datasets whose use would benefit the CEM, e.g., Chamber of Commerce registry or impact databases. A large research gap could be identified regarding the waste flow material content. To date, there is no formal ontology that connects different products and by-products with their constituent materials and consequently their potential in the circular economy. The EWC codes used in the waste registry are suitable to assign the most appropriate waste treatment method, however, have limited utility in assigning circular economy strategies and assessing their feasibility. Therefore, future work on the CEM should include developing such a material ontology and including its use in the waste registry.

The following sections discuss the learning of the mapping process according to the five requirements set forward in the theoretical framework and provide recommendations for the data improvement. At this point it is not known to which extent these lessons are applicable for the waste registries in other EU countries and if it is possible to integrate the reporting systems into a Europe-wide CEM as outlined in the CEAP. Therefore, a similar investigation is necessary in the other member countries within the European Union to whom the same reporting obligations apply. However, the discussed findings and recommendations can be used as a guidance for the improvement of the European Waste Statistics Regulation.

\subsection{Flows, Relations and Transformations}

The waste data allows tracing waste flows from their producers to the first waste management facility that receives it. Therefore, it is possible to determine the necessary geographical scale for the decision-making. E.g., the geographical extent of food waste flows is smaller than that of construction and demolition waste. It is also possible to distinguish between waste produced in the region versus the waste treated in the region. Relations between economic activities, materials and waste processing methods are in theory possible to trace, however, in practice this information proves to be unreliable or insufficiently granular.

The main limitation of studying waste flows is the lack of continuity in the data. Although secondary waste data exists, it is incomplete as not all secondary waste is required to be registered. Moreover, currently it is not possible to trace which primary waste has been turned into which secondary waste. Even when the indicated waste processing method suggests that the waste stream has not been disposed of (e.g. "Reuse as building material", "Shredding", "Separation") it is not clear which part has been effectively brought back into the economy and for which purpose and use. This prevents effective estimation of the current material circularity that passes through the waste system.

Furthermore, it is not known which process the waste has effectively originated from. As discussed in Sileryte et al. (2021b), entities that report waste are often those that pay for waste disposal rather than those that actually contributed to the waste production (e.g., administrative holdings instead of manufacturers themselves). When the actual process that causes waste production is not known or is statistically underestimated due to shifted responsibility, it is not known which policies are necessary to tackle the actual sources of waste production.

The flaws of assigning the right economic sector to the waste disposing actors also have direct influence on determining material content of a waste flow. Although some content characteristics are available in the EWC-based waste description, combining this information with the economic activity 


\section{European Waste Statistics data for a Circular Economy Monitor} the actual content or source. emission rates.

\subsection{Measurement Units} mass rather than other units. of CE strategies.

\subsection{Material Content} reuse, or up-cycling. instead of linear supply chains.

\subsection{Spatio-temporal Information}

that has produced waste may provide additional insights into material quality and potential for reuse. This is especially relevant in cases when EWC code description is based on describing which materials the waste stream does not include (e.g. "02 0699 wastes not otherwise specified") instead of describing

The mapping of waste flows to the energy needs for their transport has led to an example estimation of environmental impacts. While waste reporting should not be burdened with additional reporting of related emissions and other impacts, the reporting system should allow integrating this information from other sources. E.g., waste processing methods could be reported using the same taxonomies that are used to estimate the environmental impact of those processes. Regarding the transport-related impact, registration of the transporting vehicle would allow coupling this information with the actual

Currently, the waste registry system allows tracing the total mass of waste disposed of by one company within a month. This allows tracing the changes of waste generation patterns over time and space and roughly estimating the environmental impacts as impact databases typically relate to material

In case of waste streams that contain mixtures of materials, it is not possible to estimate the actual proportions of the different materials and, consequently, the material quality and value that can be recovered from waste. Therefore, more granular information on the waste content, including the estimated proportions of different materials or products and better indication of the material quality and origin, would allow further estimations on the actual market value and, as a result, the feasibility

The EWC codes provide standardised information on the waste content and therefore play a major role in determining the best applicable waste handling, treatment or up-cycling process for the given type of waste. However, EWC codes have been designed for the linear economy where the main problem of waste management is avoiding or minimising the negative impacts caused by collection, transport, or disposal. With the shift towards the circular economy, the main problem of the linear economy is likewise shifting towards material scarcity. Therefore, the registration of waste streams should provide insights into the material content from the perspective of waste prevention, possible

Better insights into the waste content can be achieved by either updating the EWC taxonomy or introducing a new taxonomy which describes the waste content in relation to its potential for the circular economy. Initiatives of such taxonomies or ontologies already exist in the literature as material passports (Sauter et al., 2018; Gligoric et al., 2019), supply chain tracking systems (Mboli et al., 2020) or tag recommenders (Takhom et al., 2015; Gatzioura et al., 2019). Ideally, such an improved taxonomy would allow correspondence between the established taxonomies for waste as well as product registration to allow full supply and demand modelling and design of the circular

Finally, the material content is strongly determined by the economic activity that has caused waste production. Therefore, a more detailed registration of the waste producing entity and the economic activities that preceded the waste generation would allow better estimation of material characteristics after they have entered the waste stream. This, in turn, requires an update in guidelines on which entities should be considered responsible for the waste production.

The waste reports allow for an efficient geolocation of activities. Through the high level of detail the spatial information also allows estimating the transportation distances and using them as proxies for 

2020).

\subsection{Availability of Metadata} a kilogram and it is consistent throughout all reports.

\section{A. Data and Code availability}

\footnotetext{
${ }^{1} \mathrm{http}: / / \mathrm{h} 2020$ repair.eu/

${ }^{2}$ https://www.cinderela.eu/
}

transportation costs and transport-related emissions. Temporal information is presented in timestamps that refer to the relevant year and month of disposal of the flow. It allows tracking yearly as well as seasonal changes of waste production frequency and occurrence within a certain period.

The most noticeable limitation that can be observed in Figure 1 is the presence of the national borders. Only a very insignificant number of waste reports $(<1 \%)$ register waste imports or exports. In the Netherlands, this limitation is caused by a different institution being responsible to collect waste movements across national boundaries. Therefore, it is important to note that integrating both sources of waste reports would provide a more complete picture of the actual waste system, its scale and the necessary decision making boundaries and relevant stakeholders (Graedel et al., 2019; Schaubroeck,

Currently, timestamps are available only for the month in which the waste has been transported from its producer to the processor. It does not provide information about when the waste has effectively been produced and the time needed for its storage and accumulation neither at the producer nor at the processor side. Including this information would be relevant for the estimation of space needed to change the waste system and reroute the materials that currently become waste. Additionally, recording the duration before the materials have become waste and how long it takes to bring them back into the economy would allow for a better modelling of stocks that will become available in the future.

There is limited metadata available for the waste data. The main standard nomenclature used to describe waste content is EWC codes. Entity addresses also follow a standard format of a Dutch address and postcode due to which the spatial mapping is highly successful. Finally, the reporting unit is always

The mapping of waste producers to their economic activities has revealed that the lack of standardised entity registration and identification creates difficulties for an effective matching of different databases. The semantic mapping of waste content could have used the additional description field, however, it is entered in a free-text form and therefore would require natural language processing which is an expensive procedure given the size of the dataset.

Impact assessment requires coupling local material flow data with Life Cycle Inventory databases that characterise different processes. Coupling requires the mapping of values available in one dataset to the ones available in the other according to different regional, temporal and semantic characteristics (Pauliuk et al., 2019). If a data integration scheme is not available and coupling can be performed in a variety of ways, the overall uncertainty of the impact assessment increases drastically (Pauer et al., 2020). Therefore, to assess the environmental impacts of waste processing methods, a standard classification of processes would allow data coupling with impact databases.

The most important lacking metadata relates to the data quality and completeness. At this point, the data providers are not able to estimate how much of all waste is effectively reported and how well the reports are representing reality. Since the reporting entities are required to do so for administrative reasons, the submission of high-quality reports is only motivated by occasional governmental controls. Given that the transition towards circular economy is expected to bring financial benefits to businesses, including them in the strategy discussions and tailored policies according to the Circular Economy Monitor, it would provide additional motivation for high quality of waste reporting.

Datasets used for this publication have been obtained under two Horizon 2020 projects: REPAiR ${ }^{1}$ (Resource Management in Peri-Urban Areas) and CINDERELA ${ }^{2}$ (New Circular Economy Business Model for More Sustainable Urban Construction). The data that support the findings of this study are 
available from the Waste Registry Division of the Dutch Ministry of Infrastructure and Public Works (NL: Landelijk Meldpunt Afvalstoffen (LMA) in the Netherlands. Restrictions apply to the availability of these data, which were used under license for this study. Data are not available from the authors and can only be accessed directly from the Ministry.

The research data is considered sensitive and therefore prohibited to be shared publicly by the Dutch Ministry of Infrastructure and Public Works. Data behind each of the four images in the Results section is available in an aggregated format and published along with this article. The computational workflow in this publication is executed via a series of script files published under license GNU General Public License, v2 at https://github.com/rusne/lma-data-pipeline.

\section{B. Acknowledgements}

The authors thank the CTO office at the City of Amsterdam for the collaboration, especially, JuanCarlos Goilo, Arjan Hassing and Mersiha Tepic, LMA office for sharing the data for the research purposes, especially Tjerk ter Veen for explaining all data collection subtleties. This project has received funding from the European Union's Horizon 2020 research and innovation programme under grant agreements No 688920 and No 776751.

\section{Supporting Material}

List of supporting material:

- queryl - all primary waste flows that have originated in the municipality of Amsterdam in 2018; total amount in tonnes. Location has been approximated to prevent reverse geolocation and flow association with an individual company.

- query2 - all primary waste that has been produced or treated in Amsterdam Metropolitan Area in 2018 and successfully matched with the producing economic sector; amount in tonnes.

- query3 - 200 largest waste streams produced or treated in Amsterdam Metropolitan Area in 2018 according the semantic reclassification; total amount in tonnes.

- query4 - all primary and secondary waste streams produced or treated in Amsterdam Metropolitan Area in 2018, plotted on a road network. Total amount of waste transported per each road segment and $\mathrm{CO}_{2}$-eq. emissions in tonnes.

\section{CRediT authorship contribution statement}

Rusne Sileryte: Conceptualization, Methodology, Investigation, Software, Writing - original draft. Arnout Sabbe: Conceptualization, Methodology, Partnership Management, Writing - review \& editing. Vasileios Bouzas: Software. Kozmo Meister: Semantic Mapping. Alexander Wandl: Supervision, Writing - review \& editing. Arjan van Timmeren: Supervision, Writing - review \& editing.

\section{References}

Akram, U., Quttineh, N.H., Wennergren, U., Tonderski, K., Metson, G.S., 2019. Optimizing Nutrient Recycling From Excreta in Sweden and Pakistan: Higher Spatial Resolution Makes Transportation More Attractive. Frontiers in Sustainable Food Systems 3. doi:10.3389/f sufs. 2019.00050.

Alexander, C., O’Hare, P., 2020. Waste and Its Disguises: Technologies of (Un)Knowing. Ethnos 0, 1-25. URL: https: //doi.org/10.1080/00141844.2020.1796734, doi:10.1080/00141844.2020.1796734.

van Capelleveen, G.C., 2020. Industrial Symbiosis Recommender Systems. University of Twente. 


\section{European Waste Statistics data for a Circular Economy Monitor}

Capelleveen, G.V., Amrit, C., Zijm, H., Murat, D., Abdi, A., 2021. Toward building recommender systems for the circular economy : Exploring the perils of the European Waste Catalogue. Journal of Environmental Management 277, 111430. URL: https://doi.org/10.1016/j.jenvman.2020.111430, doi:10.1016/j. jenvman.2020.111430.

Corona, B., Shen, L., Reike, D., Rosales Carreón, J., Worrell, E., 2019. Towards sustainable development through the circular economy-A review and critical assessment on current circularity metrics. Resources, Conservation and Recycling 151, 104498. URL: https://doi.org/10.1016/j.resconrec.2019.104498, doi:10.1016/j.resconrec. 2019. 104498.

European Commission, 2020. A new Circular Economy Action Plan For a cleaner and more competitive Europe. URL: https://eur-lex.europa.eu/legal-content/EN/TXT/?qid=1583933814386\&uri=COM : 2020: 98 : FIN.

Eurostat, 2013. Manual on waste statistics: A handbook for data collection on waste generation and treatment. URL: http://bookshop. europa.eu.

Eurostat, 2018. Economy-wide material flow accounts. URL: http://ec.europa.eu/eurostat/about/policies/ copyright\%OAhttps://ec . europa.eu/eurostat/documents/3859598/9117556/KS-GQ-18-006-EN-N.pdf/ b621b8ce-2792-47ff-9d10-067d2b8aac4b\%0Ahttp://epp. eurostat.ec.europa.eu/portal/page/portal/ product_details/publication?p_.

Ferretti, V., Montibeller, G., 2016. Key challenges and meta-choices in designing and applying multi-criteria spatial decision support systems. Decision Support Systems 84, 41-52. URL: http://dx.doi.org/10.1016/j.dss.2016.01.005, doi:10.1016/j.dss.2016.01.005.

Furlan, C., Wandl, A., Geldermans, B., Sileryte, R., 2020. A refined waste flow mapping method Addressing the material and spatial dimensions of waste flows in the urban territory through big data : the case of the Amsterdam Metropolitan Area. Contesti Citta territori progetti doi:10.13128/contest-11909.

Gatzioura, A., Sànchez-Marrè, M., Gibert, K., 2019. A hybrid recommender system to improve circular economy in industrial symbiotic networks. Energies 12,1-24. doi:10.3390/en12183546.

Geldermans, B., 2020. Securing Healthy Circular Material Flows In The Built Environment: The Case Of Indoor Partitioning. Ph.D. thesis. Delft University of Technology. doi:https://doi .org/10.7480/abe.2020.06.5038.

Geldermans, B., Wandl, A., Steenmeijer, M., A1., E., 2018. D3.3 Process model for the two pilot cases: Amsterdam, the Netherlands \& Naples, Italy. Technical Report. H2020 REPAiR.

Gemeente Amsterdam, 2020. Amsterdam Circular 2020-2025 Strategy. URL: https://www. amsterdam.nl/bestuur-organisatie/volg-beleid/ambities/gezonde-duurzame-stad/ amsterdam-circulair-2020-2025/.

Genc, O., van Capelleveen, G., Erdis, E., Yildiz, O., Yazan, D.M., 2019. A socio-ecological approach to improve industrial zones towards eco-industrial parks. Journal of Environmental Management 250, 109507. URL: https://doi.org/10. 1016/j · jenvman.2019.109507, doi:10.1016/j · jenvman.2019.109507.

Gligoric, N., Krco, S., Hakola, L., Vehmas, K., De, S., Moessner, K., Jansson, K., Polenz, I., Van Kranenburg, R., 2019. Smarttags: IoT product passport for circular economy based on printed sensors and unique item-level identifiers. Sensors (Switzerland) 19. doi:10.3390/s19030586.

Graedel, T.E., Reck, B.K., Ciacci, L., Passarini, F., 2019. On the spatial dimension of the circular economy. Resources 8. doi:10.3390/resources8010032.

Haberl, H., Wiedenhofer, D., Pauliuk, S., Krausmann, F., Müller, D.B., Fischer-Kowalski, M., 2019. Contributions of sociometabolic research to sustainability science. Nature Sustainability 2, 173-184. URL: http://dx.doi.org/10. 1038/s41893-019-0225-2, doi:10.1038/s41893-019-0225-2.

Harris, S., Martin, M., Diener, D., 2020. Circularity for circularity's sake? Scoping review of assessment methods for environmental performance in the circular economy. Sustainable Production and Consumption 26, 172-186. doi:10.1016/ j.spc.2020.09.018.

Jedelhauser, M., Binder, C.R., 2018. The spatial impact of socio-technical transitions - The case of phosphorus recycling as a pilot of the circular economy. Journal of Cleaner Production 197, 856-869. URL: https://doi.org/10.1016/j. jclepro.2018.06.241, doi:10.1016/j.jclepro.2018.06.241.

Klein, A., Hilster, D., Scholten, P., Van Wijngaarden, L., Tol, E., Otten, M., 2020. STREAM Freight Transport 2020 Emissions of freight transport modes. Technical Report. CE Delft. URL: www. cedelft.eu.

Krausmann, F., Lauk, C., Haas, W., Wiedenhofer, D., 2018. From resource extraction to outflows of wastes and emissions: The socioeconomic metabolism of the global economy, 1900-2015. Global Environmental Change 52, 131-140. doi:10.1016/ j.gloenvcha.2018.07.003.

Maqbool, A.S., Mendez Alva, F., Van Eetvelde, G., 2019. An assessment of European information technology tools to support industrial symbiosis. Sustainability 11, 131.

Mboli, J.S., Thakker, D.K., Mishra, J.L., 2020. An Internet of Things-enabled decision support system for circular economy business model. Software - Practice and Experience, 1-16doi:10.1002/spe. 2825.

Merriam-Webster, . Mapping. In Merriam-Webster.com dictionary.

Morseletto, P., 2020. Targets for a circular economy. Resources, Conservation and Recycling 153, 104553. URL: https: //doi.org/10.1016/j.resconrec.2019.104553, doi:10.1016/j.resconrec.2019.104553. 


\section{European Waste Statistics data for a Circular Economy Monitor}

Nuss, P., Blengini, G.A., Haas, W., Mayer, A., Nita, V., Pennington, D., 2017. Development of a Sankey Diagram of material flows in the EU economy based on Eurostat data: Monitoring of non-energy \& non- food material flows in the EU-28 for the EC Raw Materials Information System (RMIS). URL: https://dx.doi .org/10.2760/642511, doi:10.2760/642511. Obersteg, A., Arlati, A., Acke, A., Berruti, G., Czapiewski, K., Dąbrowski, M., Heurkens, E., Mezei, C., Palestino, M.F., Varjú, V., Wójcik, M., Knieling, J., 2019. Urban regions shifting to circular economy: Understanding challenges for new ways of governance. Urban Planning 4, 19-31. doi:10.17645/up.v4i3.2158.

OECD, 2020. The Circular Economy in Cities and Regions. URL: https://www.oecd-ilibrary.org/content/ publication/10ac6ae4-en, doi:https://doi.org/https://doi.org/10.1787/10ac6ae4-en.

Pauer, E., Wohner, B., Tacker, M., 2020. The influence of database selection on environmental impact results. Life cycle assessment of packaging using gabi, ecoinvent 3.6, and the environmental footprint database. Sustainability (Switzerland) 12,1-15. doi:10.3390/su12239948.

Pauliuk, S., Heeren, N., Hasan, M.M., Müller, D.B., 2019. A general data model for socioeconomic metabolism and its implementation in an industrial ecology data commons prototype. Journal of Industrial Ecology 23, 1016-1027. doi:10.1111/jiec.12890.

Pauliuk, S., Majeau-Bettez, G., Müller, D.B., Hertwich, E.G., 2016. Toward a Practical Ontology for Socioeconomic Metabolism. Journal of Industrial Ecology 20, 1260-1272. doi:10.1111/jiec. 12386.

Petit-Boix, A., Leipold, S., 2018. Circular economy in cities: Reviewing how environmental research aligns with local practices. Journal of Cleaner Production 195, 1270-1281. URL: https://doi .org/10.1016/j · jclepro. 2018.05.281, doi:10. 1016/j.jclepro.2018.05.281.

Pincetl, S., Newell, J.P., 2017. Why data for a political-industrial ecology of cities? Geoforum 85, 381-391. URL: http://dx.doi.org/10.1016/j.geoforum.2017.03.002, doi:10.1016/j.geof orum.2017.03.002.

Rahman, S.M., Kim, J., 2020. Circular economy, proximity, and shipbreaking: A material flow and environmental impact analysis. Journal of Cleaner Production 259, 120681. URL: https://doi.org/10.1016/j.jclepro.2020.120681, doi:10.1016/j.jclepro.2020.120681.

Sauter, E., Lemmens, R.L.G., Pauwels, P., 2018. CEO \& CAMO Ontologies: A circulation medium for materials in the construction industry, in: Caspeele, R., Taerwe, L., Frangopol, D.M. (Eds.), Life Cycle Analysis and Assessment in Civil Engineering: Towards an Integrated Vision. CRC Press, United Kingdom, pp. 1645-1652. URL: http://www. ialcce2018.org/\#/home, doi:10.1201/9781315228914.

Schaubroeck, T., 2020. Circular economy practices may not always lead to lower criticality or more sustainability; analysis and guidance is needed per case. Resources, Conservation and Recycling 162, 1-3. doi:10 .1016/j . resconrec . 2020 . 104977.

Sileryte, R., Gil, J., Wandl, A., van Timmeren, A., 2018. Introducing spatial variability to the impact significance assessment, in: Lecture Notes in Geoinformation and Cartography. volume part F3, pp. 189-209. doi:10.1007/978-3-319-78208-9\{\_ \}10.

Sileryte, R., Wandl, A., van Timmeren, A., 2021a. A Bottom-up Ontology-based Approach to Monitor Circular Economy: Aligning User Expectations, Tools, Data and Theory. URL: osf .io/sqcdv.

Sileryte, R., Wandl, A., van Timmeren, A., 2021b. The Responsibility of Waste Production: comparison of European Waste Statistics Regulation and Dutch National Waste Registry. URL: osf .io/p974m.

Takhom, A., Ikeda, M., Suntisrivaraporn, B., Supnithi, T., 2015. Toward Collaborative LCA Ontology Development: a ScenarioBased Recommender System for Environmental Data Qualification, in: 29th International Conference on Informatics for Environmental Protection (EnviroInfo 2015) Third International Conference on ICT for Sustainability (ICT4S 2015), Atlantis Press. pp. 157-164. doi:10.2991/ict4s-env-15.2015.18.

Tapia, C., Bianchi, M., Pallaske, G., M.Bassi, A., 2021. Towards a territorial definition of a circular economy: exploring the role of territorial factors in closed-loop systems. European Planning Studies URL: https://doi .org/10.1080/09654313. 2020.1867511.

Voskamp, I.M., Stremke, S., Spiller, M., Perrotti, D., Hoek, J.P.v.d., Rijnaarts, M.H.H., 2016. Enhanced Performance of the Eurostat Method for Comprehensive Assessment of Urban Metabolism. A Material Flow Analysis of Amsterdam. Journal of Industrial Ecology .

Wandl, A., Balz, V., Qu, L., Furlan, C., Arciniegas, G., Hackauf, U., 2019. The circular economy concept in design education: Enhancing understanding and innovation by means of situated learning. Urban Planning 4, 63-75. doi:10.17645/up. v4i3. 2147.

Yeo, Z., Low, J.S.C., Tan, D.Z.L., Chung, S.Y., Tjandra, T.B., Ignatius, J., 2019. A collaboration platform for enabling industrial symbiosis: Towards creating a self-learning waste-to-resource database for recommending industrial symbiosis transactions using text analytics. Procedia CIRP 80, 643-648.

Yu, Y., Yazan, D.M., Bhochhibhoya, S., Volker, L., 2021. Towards Circular Economy through Industrial Symbiosis in the Dutch construction industry: A case of recycled concrete aggregates. Journal of Cleaner Production 293, 126083. URL: https://doi.org/10.1016/j.jclepro.2021.126083, doi:10.1016/j.jclepro.2021.126083.

Zeller, V., Towa, E., Degrez, M., Achten, W.M., 2019. Urban waste flows and their potential for a circular economy model at city-region level. Waste Management 83, 83-94. URL: https://doi.org/10.1016/j.wasman.2018.10.034, doi:10.1016/j. wasman.2018.10.034. 